Agro-Science Journal of Tropical Agriculture, Food, Environment and Extension Volume 18 Number 1 (January 2019) pp. 39-44

ISSN 1119-7455

\title{
SENSITIVITY ASSESSMENT OF MAIZE (Zea mays L.) CULTIVARS GROWTH PARAMETERS TO AGROMETEOROLOGICAL INDICES IN ABEOKUTA, SOUTHWEST NIGERIA
}

\author{
${ }^{* 1}$ Makinde A.A., ${ }^{1}$ Eruola A.O., ${ }^{1}$ Ufoegbune G.C. and ${ }^{2}$ Ojekunle Z.O. \\ ${ }^{1}$ Department of Water Resources Management \& Agrometeorology, \\ Federal University of Agriculture, Abeokuta, Nigeria \\ ${ }^{2}$ Department of Environmental Management \& Toxicology, \\ Federal University of Agriculture, Abeokuta, Nigeria \\ *Corresponding author's email: hakmak4u@yahoo.com
}

\begin{abstract}
Growth parameters namely number of leaves, leaf area per plant and plant height were recorded in a field experiment in the late rainy season of 2016 to study the crop growth-weather relationship of four maize cultivars namely TZPB-SR-W, DMR-LSR-Y, ART/98/SW6 and BR/9928. The experimental plots were arranged in a Randomize Complete Block Design replicated three times. The crop growth parameters (number of leaves, plant height and leaf area) and selected agrometeorological indices namely rainfall, maximum and minimum temperature, relative humidity and sunshine hour were subjected to correlation analysis. The study confirmed that number of leaves for the cultivars used for this research was the most sensitive parameter to rainfall, minimum temperature and relative humidity fluctuations whereas it was least sensitive to maximum temperature and sunshine hour. Cultivars plant height and leaf area demonstrated highest sensitivity to maximum temperature and sunshine hour, respectively in the study area. The correlations coefficients $(r)$ obtained in the experiment revealed that rainfall, minimum and maximum temperature and sunshine hour were positively correlated with crop growth parameters, but relative humidity was negatively correlated with all selected growth parameters. It was recommended that number of leaves be used as the most critical factor in determining maize cultivars sensitivity to weather vagaries in the study area.
\end{abstract}

Key words: maize, agrometeorological, indices, cultivars, sensitivity

\section{INTRODUCTION}

Agrometeorological indices such as rainfall, temperature, relative humidity and sunshine hour have direct influence on the quantity and quality of agricultural production in tropical Africa. In Nigeria, agricultural production depends on weather which had been providing opportunities to use agriculture for economic means. Rainfall shortage and temperature stress are two of the most important environmental factors limiting crop growth, development, and yield (Prasad and Staggenborg, 2008; Obalum et al., 2011a). Over $80 \%$ of total global agricultural land is rainfed, with the rains often characterized by both interannual and intraseasonal variability that limits crop production (Easterling et al., 2007). For cereals, such variability could influence crop yields as much as agronomic management practices (Obalum et al., 2011b). The phenology (whole plant development rate) and physiology (functioning of internal processes) of many crops are influenced by ambient temperature. Warmer growing season temperatures can directly reduce yields in two important ways. First, higher temperatures accelerate crop growth for crops whose phenology is predominantly regulated by temperature, such as maize. This reduces the time for plant development and grain filling which limit the attainment of yield potential. Second, if extreme heat occurs during flowering, such as the maize 'silk-tasseling' phase, pollination may be inhibited and grain development may be prevented entirely.

Additionally, temperature increase could accelerate plant development to the extent that the reproductive stage, the development stage requiring the most water, would shift away from the typical wettest time of the cropping season - a problem for rainfed maize production systems. The effect of temperature in reducing the length of the growth cycle, especially the grain filling phase, is the most important factor in explaining reduced yields at warmer temperatures (White and Reynolds, 2003). Hot and dry weather both hastens pollen shed and delays silk emergence, narrowing the duration of co-occurrence. In addition, the ability of pollen to germinate on silks is greatly reduced at temperatures 
above $32^{\circ} \mathrm{C}$ (Basra, 2000). The result is fewer kernels available for filling during the reproductive period that directly follows (Herrero and Johnson, 1980). Although climatic factors can cause severe yield reductions, their effects on silk-tasseling are difficult to identify because of the short duration of the period (Porter and Semenov, 2005). The effect of temperature in reducing the length of the growth cycle, especially the grain filling phase, is the most important factor in explaining reduced yields at warmer temperatures (White and Reynolds, 2003).

Therefore, there is sufficient scope to examine correlation of weather parameters with growth attributes of maize at different phenophases under rainfed condition of western Nigerian and this form the basis of this research. Hence, this study sort to assess the sensitivity of selected maize cultivars growth parameters to selected agrometeorological indices in Abeokuta South West Nigeria.

\section{MATERIALS AND METHODS \\ Experimental Site}

The experiment was carried out in the Teaching and Research Farm of the Federal University of Agriculture Abeokuta (Latitudes $7^{\circ} 20^{\prime}$ and $7^{\circ} 32^{\prime} \mathrm{N}$, Longitudes $3^{\circ} 35^{\prime}$ and $3^{\circ} 47^{\prime} \mathrm{E}$ ), Ogun State during the 2016 cropping season (Fig. 1). Four maize cultivars were used in field trials:

- TZPB-SR-W (85 days to maturity - white), V1;

- DMR-LSR-Y (70 days to maturity - yellow), V2;

- ART/98/SW6 (70 days to maturity - yellow), V3; and

- BR/9928 (120 days to maturity - white), V4.

Three to four seeds were planted at the inter and intra-row spacing of $90 \times 30 \mathrm{~cm}$ and later thinned to one stand per hole. Each plot size was $6 \mathrm{~m}$ by 3 $\mathrm{m}$ making a total plot size of $40 \mathrm{~m} \times 15 \mathrm{~m}$ plus walking paths. The plots were weeded manually at 3 and 6 weeks after planting. The experimental plots were arranged in a Randomize Complete Block Design (RCBD) replicated three times.

\section{Data Collection}

During the phenological stages, three sets of data were collected including agrometeorological data of the plant micro-environment measured from meteorological enclosure sited near the experimental site and growth and yield parameters of the crop.

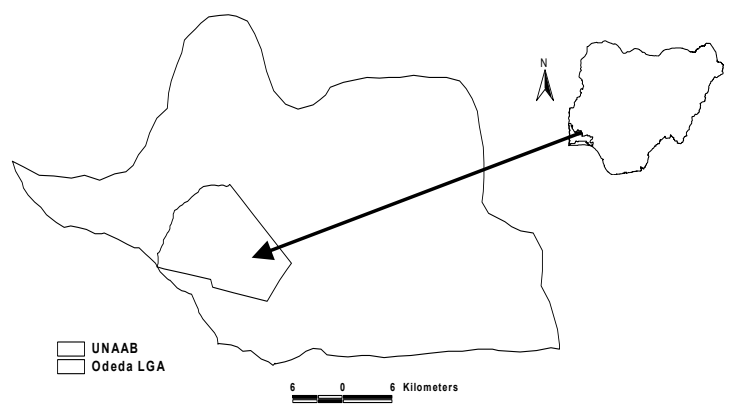

Figure 1: Map of Federal University of Agriculture, Abeokuta within Odeda Local Government Area

\section{Agrometeorological Indices}

Minimum and maximum temperature $\left(\mathrm{T},{ }^{\circ} \mathrm{C}\right)$, rainfall $(\mathrm{P}, \mathrm{mm})$, relative humidity $(\%)$, and sunshine hours, all these variables were observed at a meteorological enclosure within the vicinity of the experimental field.

\section{Growth Parameters}

The data were collected on the desired growth parameters of the crop as per treatment by using standard procedures. Major growth parameters considered includes: Plant height, Leaf area and number of leaves, measurement started 4 weeks after planting. These were determined by randomly selecting any five plant stands in each plot and these selected stands are monitored throughout the sampling period.

\section{Statistical Analysis}

The data were subjected to correlation analysis of established methods by Steel et al. (1997) using the PROC GLM procedure of the SAS Statistics package (SAS Institute Inc., 2000). The cultivars were considered as random effect and mean differences were separated using Fishers' protected least significant difference (LSD) test at $P \leq 0.05$.

\section{RESULTS AND DISCUSSION}

Weather Trend within the Micro-Climatic Environment during the Experimental Period Two weeks into the experiment, rainfall was at its minimum with the value $1.3 \mathrm{~mm}$, but with an extension of time up to 9 weeks, an increase of rainfall was recorded with a value of $102.4 \mathrm{~mm}$. Relative humidity during the period of the experiment increases at the onset from 51.4 at week 1 to 63.3 at week 3 , it decreased to 61.3 at week 4 and increases to 64.0 at week 5 before it then decreased gradually to 51.4 at week 8 . Relative humidity during the period of the experiment was at its minimum at week 1 and week 8 with a value of 51.4 and was at its maximum at week 5 with a value of 64.0. Minimum and maximum temperature has a slight fluctuation throughout the experimental period. The sunshine hour during the experimental period reaches its peak at week 10 after the fluctuation from week 4 to week 8 (Fig. 2).

Figure 3 shows that rainfall has weak positive correlation coefficients ( $r$ ) with leaf area across the four cultivars used. The figure revealed that correlation coefficients of rainfall against all the growth parameters were positively correlated with cultivars number of leaves having comparatively higher $\mathrm{r}=0.39$, while plant height and leaf area of both cultivars have $r=0.38$. The correlation coefficients of rainfall against cultivar leaf area confirmed that cultivars BR/9928(V4) and TZPBSR-W (V1) have the highest $\mathrm{r}$ of 0.38 , followed by ART/98/SW6 (V3) with $r$ of 0.37 , while the lowest value of $r$ was observed for DMR-LSR-Y (V2). The 


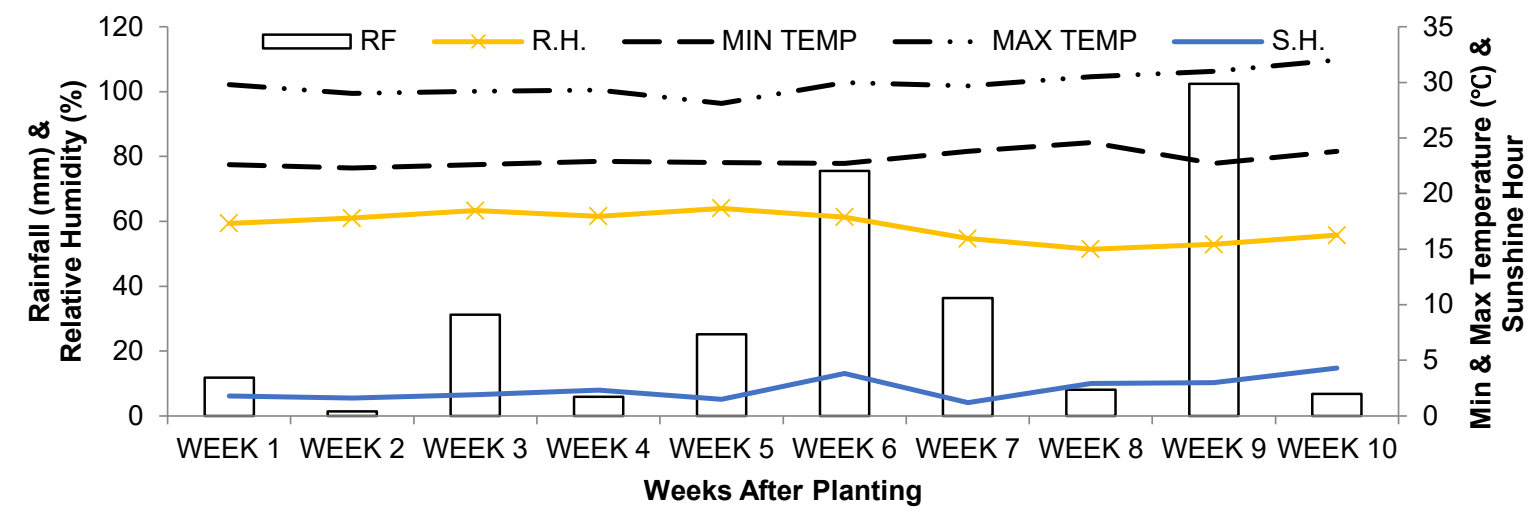

Figure 2: Weather trend within the micro-climatic environment of maize cultivars during the experimental period

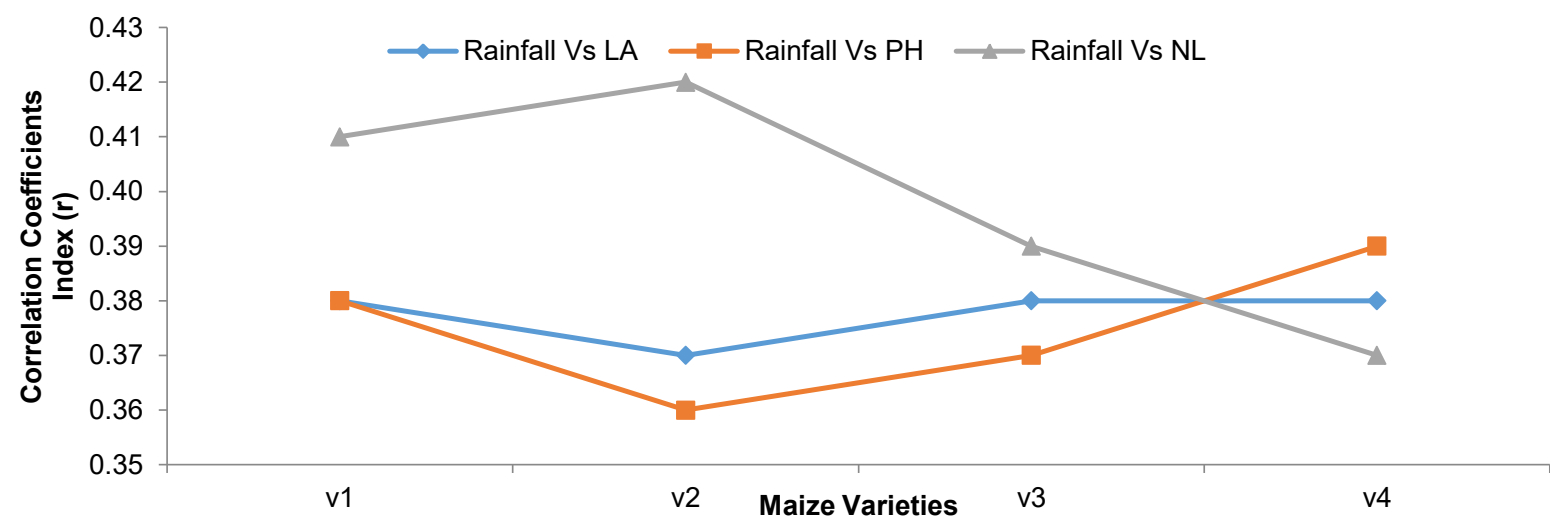

Figure 3: Correlation coefficients index of microclimatic rainfall against the leaf area, plant height and number leaves of maize cultivars at Federal University of Agriculture, Abeokuta

correlation coefficients of rainfall against the plant height follow a similar trend as observed with the leaf area across the cultivars. The plant height of cultivar BR/9928 (V4) gave the highest positive coefficient of $r=0.39$, followed by the plant height of V1 $(r=0.38)$ and V3 $(r=0.37)$, while the lowest correlation coefficient of $r=0.36$ was observed for V2. The correlation coefficient of rainfall with the cultivar number of leaves showed that V2 had the highest coefficient of $\mathrm{r}=0.42$ followed by V1 with $\mathrm{r}=0.41$ then $\mathrm{V} 3$ with $\mathrm{r}=0.39$, while lowest coefficient was recorded for V4 with $\mathrm{r}=0.37$. Generally, cultivars number of leaf showed highest response or utilization of rainfall during the maize growth in the study area (Fig. 3). Similar findings have been reported by Dreyer et al. (1981) and Murthy and Rao (2000).

Figure 4 presents correlation analysis of minimum temperature against the cultivars leaf area, plant height and number of leaves for the maize cultivars. There was strong positive correlation coefficient between minimum temperature and cultivar leaf area, plant height and number of leaves of all the cultivars. The figure revealed that correlation coefficients of minimum temperature against all the growth parameters were positively correlated with cultivars number of leaves having comparatively higher correlation coefficient of $r=0.67$ while plant height and leaf area of both cultivars have correlation coefficient of $r=0.65$. The correlation coefficient of minimum temperature against number of leaf revealed that cultivars DMR-LSR-Y (V2), ART/98/SW6 (V3) and BR/9928 (V4) have the same correlation coefficients of $r=0.67$, while only TZPB-SR-W (V1) showed slightly lower correlation coefficient of $r=0.66$. The correlation coefficients of minimum temperature against the plant height of maize cultivars equally follow a similar trend as observed with the number of leaves of maize cultivars. The plant height of cultivars TZPB-SRW (V1), DMR-LSR-Y-V2 and BR/9928 (V4) gave the same positive coefficient of $r=0.65$ while only cultivar ART/98/SW6 (V3) has $r=0.64$.

The result of correlation coefficient of minimum temperature against the cultivars leaf area confirmed a similar pattern with number of leaves of cultivars. Maize cultivars DMR-LSR-Y (V2), ART/98/SW6 (V3) and BR/9928 (V4) have the same $r$ value of 0.66 , while only TZPB-SR-W (V1) gave slightly lower correlation coefficient of $r$ $=0.63$. The cultivars number of leaves appeared to be most susceptible to minimum temperature fluctuations followed by cultivar leaf area, while cultivar plant height was the least influenced by minimum temperature in the study area. Nigam et al. (1994) reported similar effect of temperature and photoperiod on groundnut crop. 


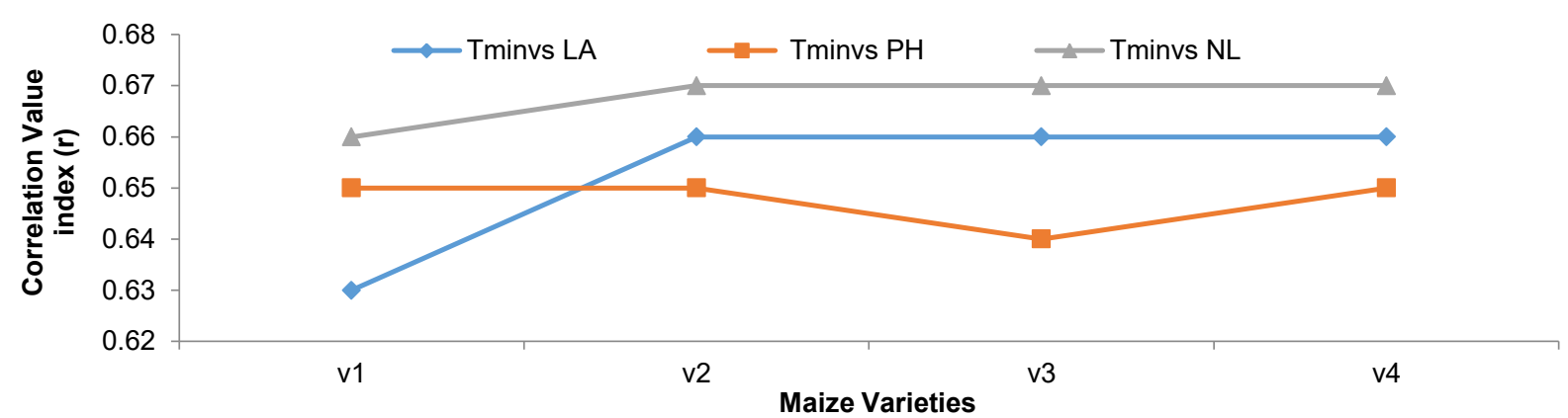

Figure 4: correlation coefficients index of microclimatic minimum temperature against leaf area, plant height and number leaves of maize cultivars at Federal University of Agriculture, Abeokuta

The result of correlation analysis of maximum temperature with cultivars leaf area, plant height and number of leaves is as presented in Figure 5. The figure revealed that correlation coefficients of maximum temperature against all the growth parameters were positively correlated with cultivars leaf area having comparatively higher correlation coefficient of $r=0.73$ followed by cultivars plant height with coefficient of $r=0.72$, while cultivar leaf area have correlation coefficient of $r=0.68$. The correlation coefficient of maximum temperature against cultivar number of leaves revealed that cultivar BR/9928 (V4) has the height correlation coefficient of $r=0.68$, followed by cultivar TZPB-SR-W (V1) with $\mathrm{r}=0.64$ then cultivar DMR-LSR-Y (V2) with $r=0.63$ while the least coefficient of $r=0.61$ was observed for the cultivar ART/98/SW6 (V3). The correlation coefficients of maximum temperature against the cultivar plant height shows that cultivar DMRLSR-Y (V2) has higher correlation coefficient of $r$ $=0.78$ followed by cultivar ART/98/SW6 (V3) with correlation coefficient of $r=0.75$, then cultivar TZPB-SR-W (V1) with $r=0.68$, while the least correlation coefficient of $r=0.67$ was obtained by cultivar BR/9928 (V4). Correlation coefficients of maximum temperature against the leaf area varies from $\mathrm{r}=0.72$ for cultivars DMR-LSR-Y (V2) and ART/98/SW6 (V3), then $r=0.73$ for cultivar BR/9928 (V4) to $r=0.75$ for cultivar TZPB-SR-W (V1). The cultivars number of leaf appeared to be least susceptible to maximum temperature fluctuations then cultivars leaf area, while cultivars plant height was the most influenced by maximum temperature especially cultivars DMR-LSR-Y (V2) and ART/98/SW6 (V3) in the study area.

The findings were similar to Wardlaw et al. (1980) and Peng et al. (2004) who worked on how diurnal asymmetry of temperature changes can impact different plant physiological processes, and effects on growth and yield of maize.

The response of leaves area, plant height and number of leaves of cultivars to relative humidity is shown in Figure 6. The figure shows that correlation coefficients of relative humidity with all the growth parameters are negatively correlated. The figure again revealed that cultivars number of leaves had comparatively higher correlation coefficient of $r=-0.34$, while both cultivars plant height and leaf area have correlation coefficient of $r$ $=-0.37$. The correlation coefficients of relative humidity against cultivars number of leaves ranged from $\mathrm{r}=-0.36$ for cultivar BR/9928 (V4), then $\mathrm{r}=$ -0.35 and -0.34 for cultivars TZPB-SR-W (V1) and DMR-LSR-Y (V2), respectively, while the highest correlation coefficient of $\mathrm{r}=-0.31$ was observed for cultivar ART/98/SW6 (V3). The correlation coefficient of relative humidity against cultivars leaf area varied from $r=-0.38$ for cultivar $\mathrm{BR} / 9928$ (V4), then $\mathrm{r}=-0.37$ for cultivars DMRLSR-Y (V2) and ART/98/SW6 (V3), while the highest value of $r=-0.36$ was observed for cultivar TZPB-SR-W (V1). The correlation coefficient of relative humidity against cultivars plant height varied from $\mathrm{r}=-0.43$ for cultivar DMR-LSR-Y (V2), then $r=-0.39$ for cultivar ART/98/SW6 (V3) to $\mathrm{r}=-0.34$ for cultivar TZPB-SR-W (V1), while the highest value of $r=-0.33$ was observed for cultivar BR/9928 (V4).

The response of the cultivars leaves area, plant height and number of leaves to variation in sunshine hour is shown in Figure 7. The figure revealed that correlation coefficients of sunshine hour with all the growth parameters were positively correlated with cultivar leaf area has the correlation coefficient with mean value of $r=0.68$ followed by cultivars plant height with correlation coefficient of $r=0.67$, while the least coefficient of $r=0.61$ was observed for cultivar number of leaves. The correlation coefficients of sunshine hour against cultivars number of leaves ranged from $r=0.59$ for cultivar ART/98/SW6 (V3), then $r=0.6$ for cultivar DMR-LSR-Y (V2) while cultivars TZPBSR-W (V1) and BR/9928 (V4) have highest correlation coefficient of $r=0.62$. The correlation coefficient of sunshine hour against cultivars plant height varied from $r=0.65$ for cultivars TZPB-SR$\mathrm{W}$ (V1) and BR/9928 (V4), then $\mathrm{r}=0.68$ for cultivar ART/98/SW6 (V3), while the highest coefficient of $r=0.70$ was observed for cultivar DMR-LSR-Y (V2). The correlation coefficient of sunshine hour against cultivars leaf area varied from $r=0.66$ for cultivar ART/98/SW6 (V3), then $r=0.67$ for both cultivars DMR-LSR-Y (V2) and BR/9928 (V4), while cultivar TZPB-SR-W (V1) has the highest coefficient of $r=0.72$. 


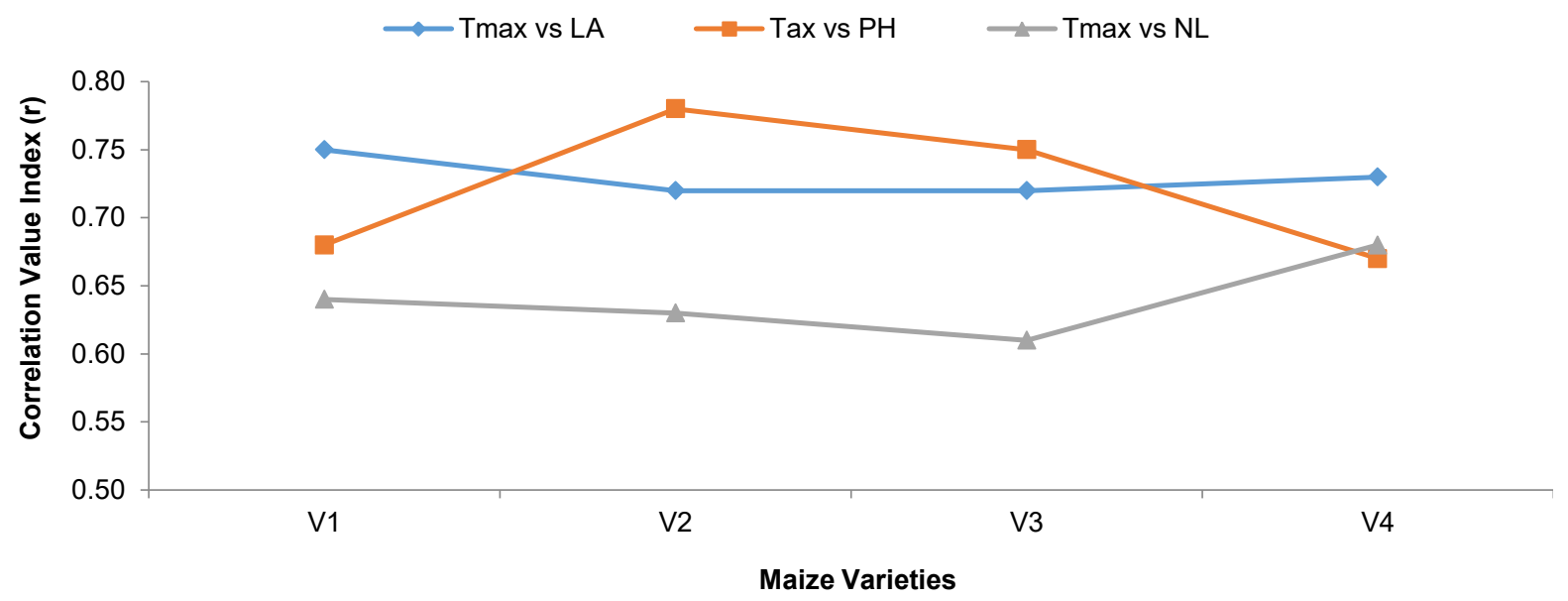

Figure 5: Correlation coefficients index of microclimatic maximum temperature against leaf area, plant height and number leaves of maize cultivars at Federal University of Agriculture, Abeokuta

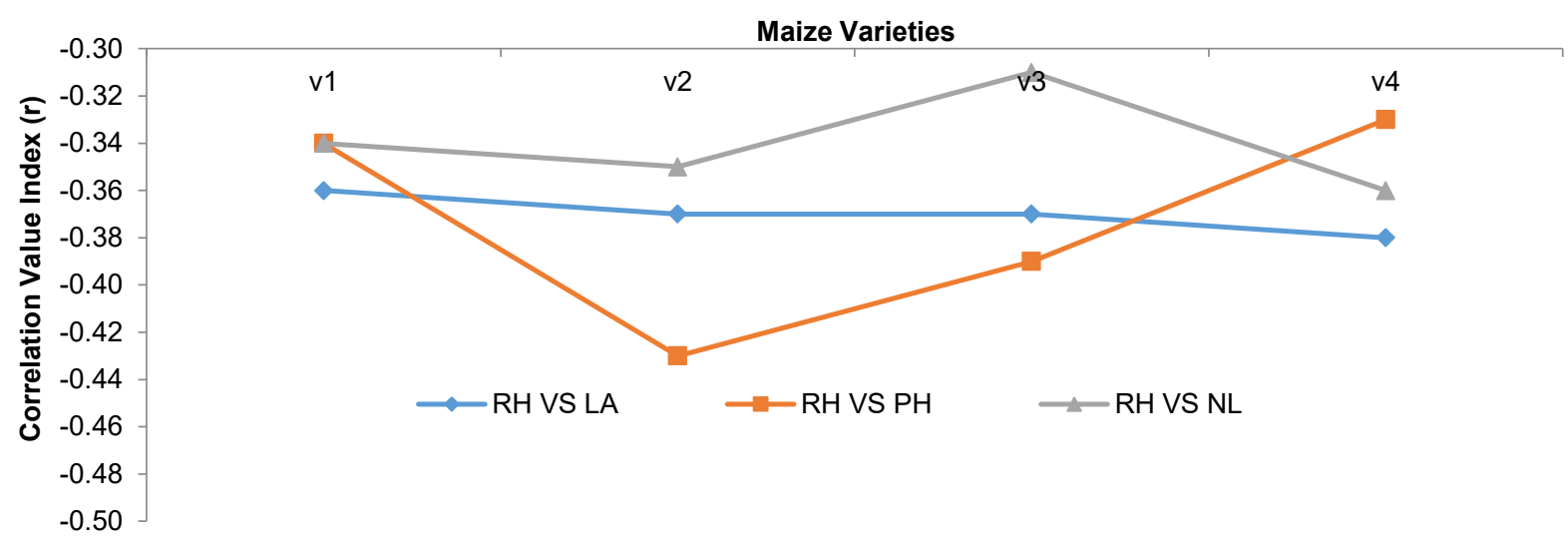

Figure 6: Correlation coefficients index of microclimatic relative humidity against leaf area, plant height and number leaves of maize cultivars at Federal University of Agriculture, Abeokuta

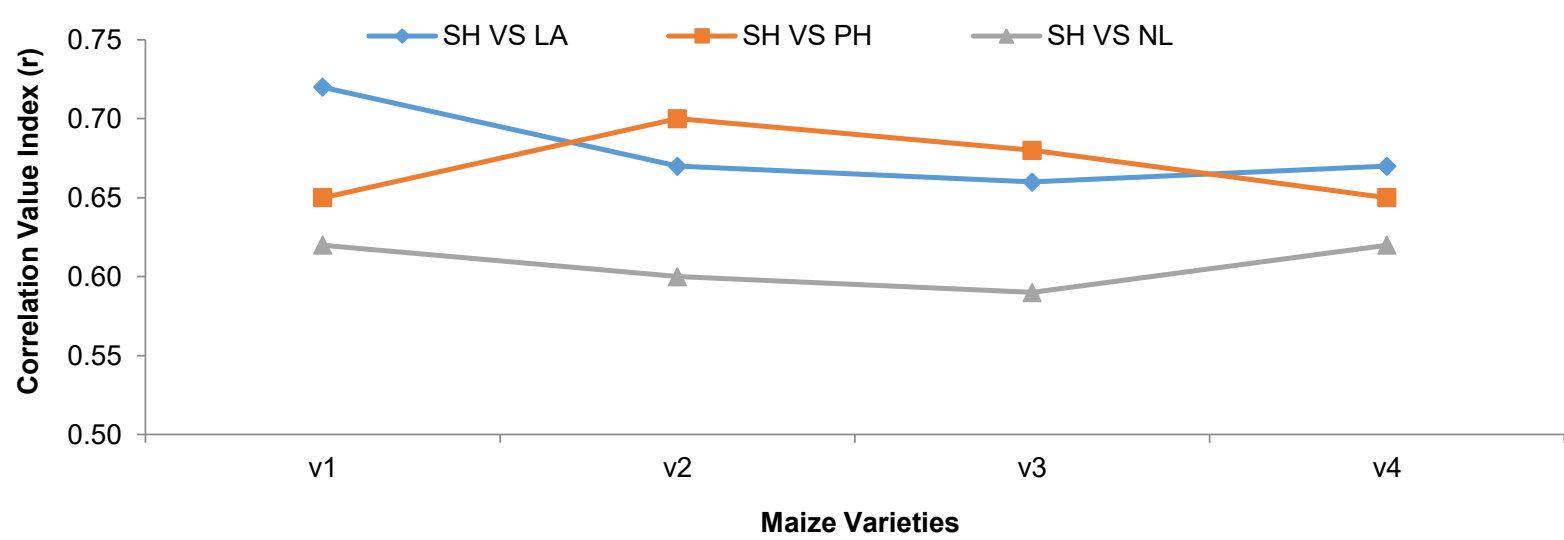

Figure 7: Correlation coefficients index of microclimatic sunshine hour against leaf area, plant height and number leaves of maize cultivars at Federal University of Agriculture, Abeokuta

\section{CONCLUSION AND}

\section{RECOMMENDATION}

The study confirmed that Number of leaves of cultivars used for this research was the most sensitive parameter to rainfall, minimum temperature and relative humidity fluctuations, whereas it was least sensitive to maximum temperature and sunshine hour in the study area.
Cultivar plant height was the most sensitive to maximum temperature, while cultivar leaf area was most sensitive to sunshine hour in the study area. Therefore, it was recommended that number of leaves remains the most important factor in determining maize cultivars sensitivity to weather vagaries in Federal University of Agriculture, Abeokuta, Southwest Nigeria. 


\section{REFERENCES}

Basra A.S. (2000). Crop responses and adaptations to temperature stress. Food Products Press, New York.

Dreyer J., Duncan W.G. and McCloud D.L. (1981). Fruit temperature, growth rate and yield of peanuts. Crop Sci., 21, 686-688

Easterling W.E., Aggrawal P.K., Batima P. and Brander K.M. (2007). Food, fibre, and forest products. In: Parry M.L., Canziani O.F., Palutikof J.P., Hanson C.E., van der Linden P.J. (Eds.) Climate Change 2007: Impacts, Adaptation and Vulnerability. Contribution of Working Group II to the Fourth Assessment Report of the IPCC. Cambridge University Press, Cambridge, pp. 273-313

Herrero M.P. and Johnson R.R. (1980). High temperature stress and pollen viability of maize. Crop Sci., 20, 796-800

Murthy S.K.K. and Rao A.Y. (2000). Correlation between weather parameters at different phenophases and growth and yield parameters of groundnut (Arachis hypogaea L.). Annals of Arid Zone, 39, 23-33

Nigam S.N., Rao R.C.N., Wynne J.E., Williams J.H., Fitzner M. and Nagabhushanam G.V.S. (1994). Effect and interaction of temperature and photoperiod on growth and partitioning in three groundnut (A. hypogaea L.) genotypes. Annals of Applied Biology, 125, 541-552

Obalum S.E., Amalu. U.C., Obi M.E., and Wakatsuki T. (2011b). Soil water balance and grain yield of sorghum under no-till versus conventional tillage with surface mulch in the derived savanna zone of southeastern Nigeria. Experimental Agriculture, 47, 89-109
Obalum S.E., Ezenne G.I., Watanabe Y. and Wakatsuki T. (2011a). Contemporary global issue of rising water scarcity for agriculture: the quest for effective and feasible soil moisture and free-water surface conservation strategies. Journal of Water Resource and Protection, 3 (3), 166-175

Peng S, Huang J, Sheehy J.E, and Laza R.C. (2004). Rice yields decline with higher night temperature from global warming. Proc. Natl. Acad. Sci USA 101, 9971-9975

Porter J.R. and Semenov M.A. (2005). Crop responses to climatic variation. Philos Trans $R$ Soc Lond B Biol. Sci., 360, 2021-2035

Prasad P.V.V. and Staggenborg S.A. (2008). Impacts of drought and/or heat stress on physiological, developmental, growth, and yield processes of crop plants. In: Ajuha L.R., Reddy V.R., Saseendran S.A. and Yu Q. (Eds.) Response of Crops to Limited Water: Understanding and Modeling Water Stress Effects on Plant Growth Processes. Am. Soc. Agron., Mad., WI, pp. 301-356

SAS Institute Inc. (2000). 'The SAS System. SAS online Doc.HTMLFormat. Version 8.' (SAS Institute: Cary, NC)

Steel R.G.D., Torrie J.H and Dickey D.A. (1997). Principles and procedures of statistics: a biometrical approach. 3rd edn (McGraw-Hill: New York)

Wardlaw I.F, Sofield I. and Cartwright P.M. (1980). Factors limiting the rate of dry matter accumulation in the grain of wheat grown at high temperatures. Aust. J. Plant Physiol., 7, 387-400

White J.W. and Reynolds M.P. (2003). A physiological perspective on modeling temperature response in wheat and maize crops. In: White JW (ed.) Modeling temperature response in wheat and maize. Proc. of a Workshop, CIMMYT, El Batán, Mexico, 23-25 April 2001. CIMMYT, Mexico City, p 8-17 